\title{
Inhibitory action of two zinc oxide sources on the ex vivo growth of porcine small intestine bacteria
}

\author{
W. Vahjen,* J. Zentek,* and S. Durosoy $\dagger^{1}$ \\ *Free University of Berlin, Faculty of Veterinary Medicine, Institute of Animal Nutrition, Germany; \\ $†$ Animine, Sillingy, France
}

\begin{abstract}
Pharmacological dosage of zinc oxide in piglet weaning diets is a common practice to improve growth performance and gut health. However, high zinc excretion in animal wastes poses environmental challenges. Alternatives to current practice are studied. In this study, the inhibitory action of 2 zinc oxide sources on the ex vivo growth of small intestinal bacteria from
\end{abstract}

weaned piglets was studied. Lag time was higher $(P$ $<0.05)$ in media supplemented with a new zinc oxide preparation in stomach samples, but not in jejunum samples. Bacterial growth reduction $(P<0.05)$ was more drastic and more rapid in media supplemented with the new zinc oxide preparation.

Key words: antibacterial activity, piglet, zinc oxide

(C) 2012 American Society of Animal Science. All rights reserved.

J. Anim. Sci. 2012.90:334-336 doi:10.2527/jas52921

\section{INTRODUCTION}

The use of pharmacological dosages of zinc oxide is a common practice in piglet weaning diets with welldocumented beneficial effects on growth performance and gut health (Poulsen, 1995; Carlson et al., 2008). Studies with piglets show reduced lactic acid bacteria and increased coliforms (Hojberg et al., 2005) and reduced anaerobic and lactic acid bacteria, but no effect on Escherichia coli (Broom et al., 2006) or changes in lactic acid bacteria composition, and an increase in enterobacterial diversity (Vahjen et al., 2010, 2011) with high doses of $\mathrm{ZnO}$. However, high zinc excretion in animal wastes poses environmental challenges (Jondreville et al., 2003). Therefore, a reduced zinc concentration in farm manure is preferred. This study was conducted to compare the effect of a new form of zinc oxide with analytical grade zinc oxide.

\section{MATERIAL AND METHODS}

\section{Samples and Growth Conditions}

Stomach and jejunal chyme from 42-d-old piglets (n $=6$ ) fed a standard European diet were transferred into an anaerobic atmosphere $\left(95 \% \mathrm{~N}_{2}, 5 \% \mathrm{H}_{2}\right)$ and diluted (1:10 vol/vol) in reinforced clostridial medium (RCM). After sedimentation for $5 \mathrm{~min}, 20 \mu \mathrm{L}$ suspensions were taken with sterile cut pipette tips and inoculated into microtiter plate wells.

\section{Generation of Zn-containing Media and Incubation Conditions}

Zinc-saturated media (analytical grade $\mathrm{ZnO}$ p.a., Sigma, Deisenhofen, Germany; HiZox, Animine, Sillingy, France) were produced by adding $10 \mathrm{~g}$ of zinc source to $100 \mathrm{~mL}$ of RCM, $\mathrm{pH} 6.5$, stirring for $1 \mathrm{~h}$ at room temperature, autoclaving $\left(121^{\circ} \mathrm{C}, 15 \mathrm{~min}, 1 \mathrm{bar}\right)$, and centrifuging $\left(10,000 \times \mathrm{g}, 10 \mathrm{~min}, 4^{\circ} \mathrm{C}\right)$. A new zinc oxide preparation (HiZox) is a standardized product obtained with a patented manufacturing process that results in specific product features (unique particle size and shape, elevated surface area). Supernatants were analyzed by atomic absorption spectrometry (Analytik, Jena, Germany) for total zinc concentrations. Media were adjusted to an identical $\mathrm{Zn}$ concentration $(80 \mu \mathrm{g} /$ $\mathrm{mL}$ ) and diluted with RCM (final concentrations: 80 , 40, 20, and $10 \mu \mathrm{g} \mathrm{ZnO} / \mathrm{mL}$ medium). Under anaerobic working conditions, intestinal sample dilutions $(20 \mu \mathrm{L})$ were inoculated into $180 \mu \mathrm{L}$ of medium in microtiter plates with increasing zinc concentrations. A microplate reader with anaerobic incubation capacity (TecanInfinitePro, Groedig, Austria) was used to record turbidity every 5 min over a period of $22 \mathrm{~h}$.

${ }^{1}$ Corresponding author: sdurosoy@animine.eu 

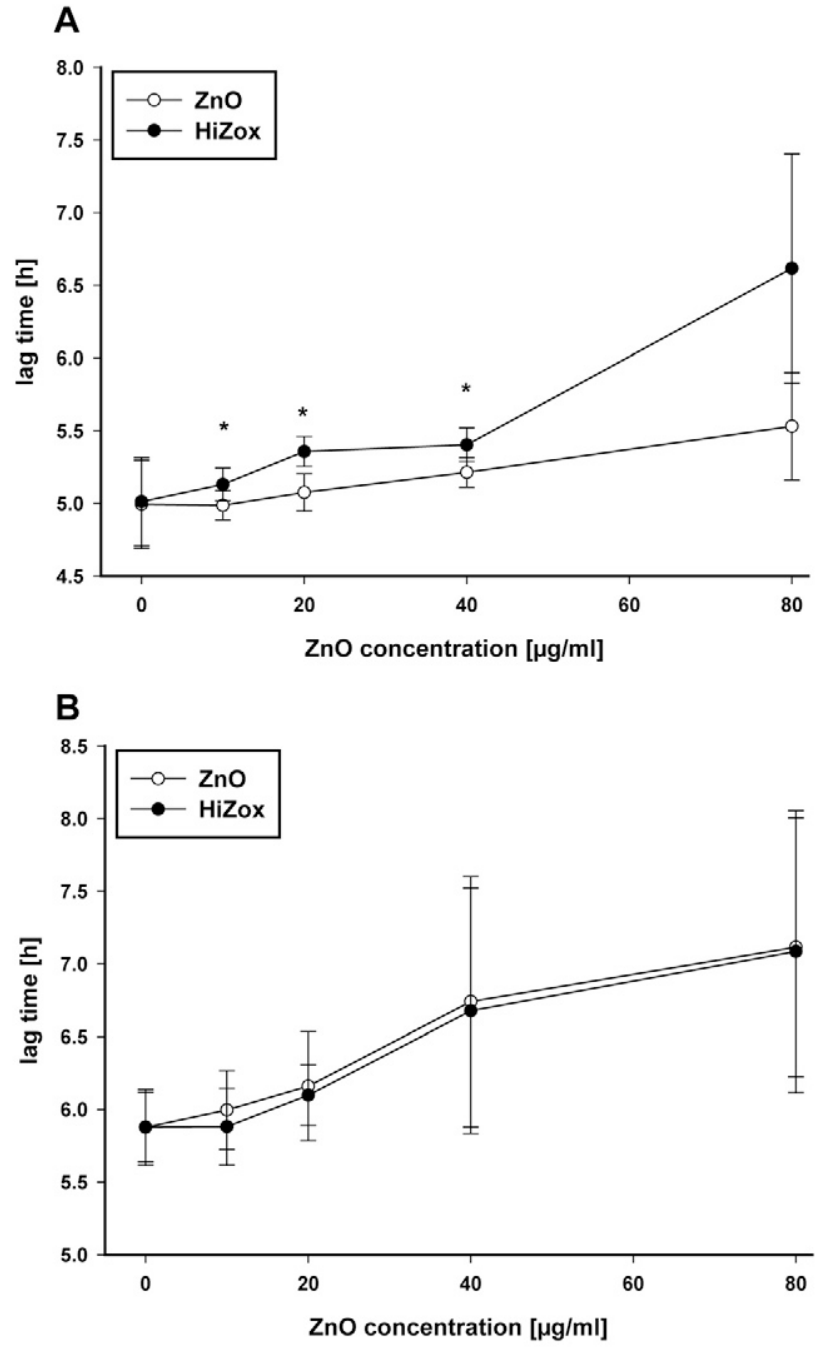

Figure 1. Calculated lag times of bacterial growth from intestinal samples after 22-h growth at different $\mathrm{Zn}$ concentrations (OD $650 \mathrm{~nm}$ ); (A) stomach; (B) jejunum. *Significantly different $(P \leq 0.05)$

\section{Data Evaluation and Statistics}

Turbidity data were transformed into growth curves and analyzed with a nonlinear regression analysis (3-sigmoidal curve fit) for lag time (h). Additionally, 3-dimensional plots of incubation time vs. $\mathrm{ZnO}$ concentration vs. OD of Zn-supplemented media subtracted from control incubations was used to visualize the initial growth depression of the different zinc sources. Growth data from different zinc sources was compared at each zinc concentration using the $t$-test. The level of significance was set to $P \leq 0.05$.

\section{RESULTS AND DISCUSSION}

The new zinc oxide preparation showed higher solubility than analytical grade $\mathrm{ZnO}$. At $\mathrm{pH} 6.5$ a $1.4-$ fold increase of solubility was observed $(640 \mu \mathrm{g} / \mathrm{mL}$ and $878 \mu \mathrm{g} / \mathrm{mL}$ for $\mathrm{ZnO}$ and the new zinc oxide preparation, respectively).
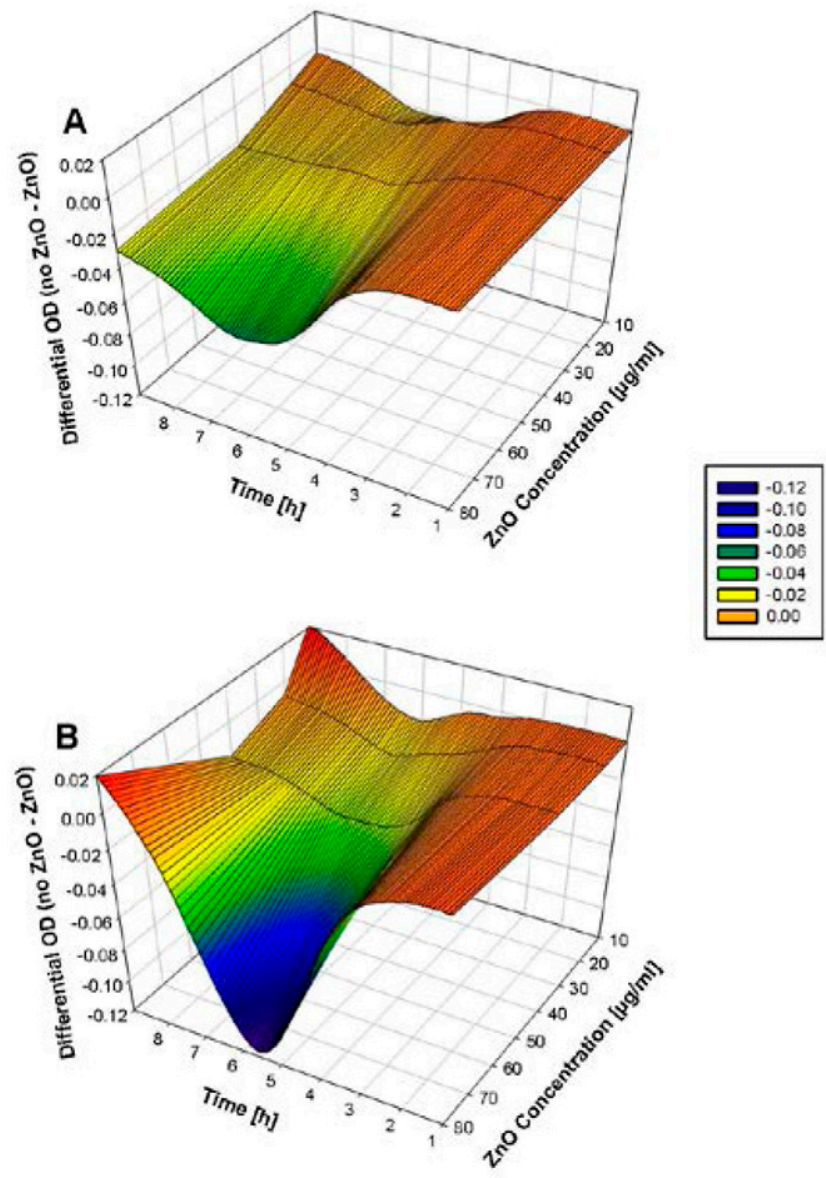

Figure 2. Three-dimensional presentation of the initial growth depression of bacteria in stomach samples as differential OD (subtraction of OD from $\mathrm{ZnO}$ supplemented media from control incubations; mean of 6 incubations). (A) ZnO p.a.; (B) HiZox, Animine, Sillingy, France.

\section{Lag Time for Growth of Intestinal Bacteria from Stomach and Jejunum Samples}

The onset of bacterial growth in stomach samples was slower in media supplemented with the new zinc oxide preparation than in media supplemented with analytical grade $\mathrm{ZnO}$ (Figure 1A). Jejunal samples did not show any differences between zinc sources (Figure 1B). The increased solubility of the new zinc oxide preparation may be responsible for the observed increased lag time in the stomach because the low $\mathrm{pH}$ in the stomach increases solubility of zinc oxide. Due to an increased "bioaccessibility," actual free zinc concentrations may have varied between the 2 zinc sources, although total zinc concentrations were identical. The increased lag times for the new zinc oxide preparation in the stomach, but no changes between zinc sources in the small intestinal samples may be the outcome of growth reduction for lactic acid bacteria in the stomach, while more diverse bacterial groups in the jejunum could show a higher adaptation to zinc and consequently faster growth.

Three-dimensional presentations of the data were chosen in order to display the initial bacterial growth depression, because the physiological state of a bacterial 

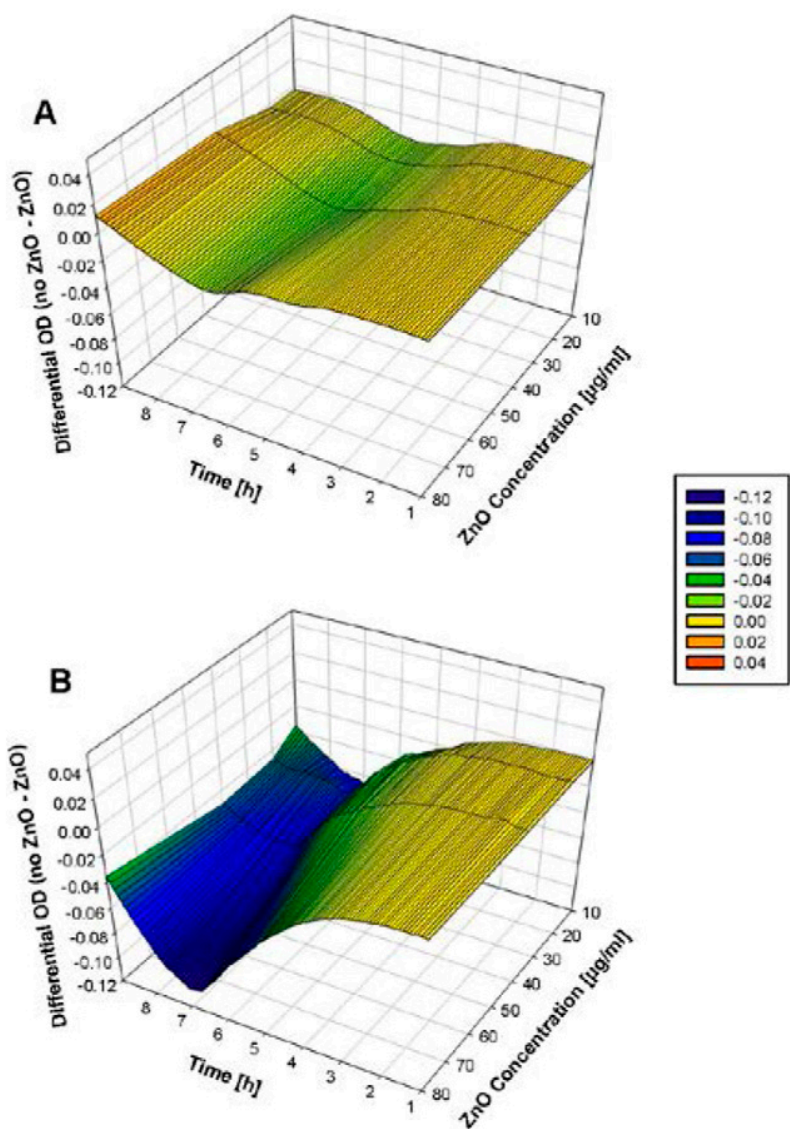

Figure 3. Three-dimensional presentation of the initial growth depression of bacteria in jejunum samples as differential OD (subtraction of OD from $\mathrm{ZnO}$ supplemented media from control incubations; mean of 6 incubations). (A) ZnO p.a.; (B) HiZox, Animine, Sillingy, France.

cell determines its further success to compete against other bacteria. The new zinc oxide preparation led to a more drastic and earlier decline of OD in stomach samples (Figure 2) and jejunum samples (Figure 3). These results again confirm that higher bioaccessible $\mathrm{Zn}^{2+}$ concentrations must have been present in media supplemented with the new zinc oxide preparation.

In conclusion, the new zinc preparation exhibited higher growth depressing effects than analytical grade $\mathrm{ZnO}$ because of its different physico-chemical properties. Consequently, its concentration in feed could be reduced and therefore decrease zinc excretion.

\section{LITERATURE CITED}

Broom, L. J., H. M. Miller, K. G. Kerr, and J. S. Knapp. 2006. Effects of zinc oxide and Enterococcus faecium SF68 dietary supplementation on the performance, intestinal microbiota and immune status of weaned piglets. Res. Vet. Sci. 80:45-54

Carlson, D., J. Sehested, Z. Feng, and H. D. Poulson. 2008. Serosal zinc attenuate serotonin and vasoactive intestinal peptide induced secretion in piglet small intestinal epithelium in vitro. Comp. Biochem. Physiol. A Mol. Integr. Physiol. 149:51-58.

Hojberg, O., N. Canibe, H. D. Poulsen, M. S. Hedemann, and B. B. Jensen. 2005. Influence of dietary zinc oxide and copper sulfate on the gastrointestinal ecosystem in newly weaned piglets. Appl. Environ. Microbiol. 71:2267-2277.

Jondreville, C., P. S. Revy, and J. Y. Dourmad. 2003. Dietary means to better control the environmental impact of copper and zinc by pigs from weaning to slaughter. Livestock Production Science 84:147-156.

Poulsen, H. D. 1995. Zinc oxide for weanling piglets. Acta Agric. Scand. A, Anim. Sci. 45:159-167.

Vahjen, W., R. Pieper, and J. Zentek. 2010. Bar-coded pyrosequencing of 16S rRNA gene amplicons reveals changes in ileal porcine bacterial communities due to high dietary zinc intake. Appl. Environ. Microbiol. 76:6689-6691.

Vahjen, W., R. Pieper, and J. Zentek. 2011. Increased dietary zinc oxide changes the bacterial core and enterobacterial composition in the ileum of piglets. J. Anim. Sci. 89:2430-2439. 